\title{
PERANCANGAN SISTEM INFORMASI AKADEMIK ONLINE MENGGUNAKAN BLACK BOX TESTING PADA SEKOLAH TINGGI ILMU EKONOMI SURYA NUSANTARA
}

\author{
Harmonvikler Dumoharis Lumbanraja \\ Sekolah Tinggi Ilmu Ekonomi Surya Nusantara
}

\begin{abstract}
Abstrak
Pembuatan Sistem Informasi Akademik Sekolah Tinggi Ilmu Ekonomi Surya Nusantara, Pematangsiantar menggunakan pendekatan terstruktur, sedangkan metode pengembangan menggunakan prototipe dengan teknik perancangan yang didahului dengan pengumpulan data observasi dan wawancara yang diklasifikasikan dalam tahapan metode Waterfall. Sedangkan alat yang digunakan dalam mendesain sistem berupa Use Case Diagram, HTML, PHP, Javascript, CSS dan menggunakan beberapa perangkat lunak seperti XAMPP, Browser, StarUML, Sublime Text 3, Notepad ++. Pengujian sistem ini menggunakan pengujian Black box, dimana jenis pengujian ini dianggap paling tepat untuk mewakili penggunaan menu yang dibuat. Sistem yang dibangun disajikan pada server klien sehingga dapat diakses oleh semua pengguna dosen dan mahasiswa. Sistem yang dibangun diharapkan dapat mengatasi sebagian besar masalah yang ada seperti melaporkan nilai siswa secara online, mengisi formulir pendaftaran online KRS online. Sistem informasi akademik online diharapkan terus dikembangkan untuk menangani setiap kebutuhan di biro administrasi akademik Sekolah Tinggi Ilmu Ekonomi Surya Nusantara, Pematangsiantar.
\end{abstract}

Kata-kata kunci: Black box Testing, Database Analasys, Online Registration, Use Case Diagram.

\section{DESIGN OF ONLINE ACADEMIC INFORMATION SYSTEM USING BLACK BOX TESTING ATSEKOLAH TINGGI ILMU EKONOMI SURYA NUSANTARA}

\begin{abstract}
Making of Academic Information System of Sekolah Tinggi Ilmu Ekonomi Surya Nusantara, Pematangsiantar uses a structured approach, while the method of development using prototype with designing technique that was preceded by the collection of observation data and interviews are classified in the Waterfall method stages. While the tools used in designing the system form Use Case Diagrams, HTML, PHP, Javascript, CSS and use some software such as XAMPP, Browser, StarUML, Sublime Text 3, Notepad + +. The testing of this system using Black box testing, where this type of testing is considered the most appropriate to represent the use of menus are made. The built system is presented on a client server so that it can be accessed by all users of lecturers and students. The system built is expected to overcome most of the existing problems such as reporting the value of students online, online registration form input KRS online. Online academic information system is expected to continue to be developed to handle every need in academic administration bureau of Sekolah Tinggi IImu Ekonomi Surya Nusantara, Pematangsiantar.
\end{abstract}

Key Words: Black box Testing, Database Analasys, Online Registration, Use Case Diagram.

\section{Pendahuluan}

Era globalisasi saat ini, kualitas pelayanan dipandang sebagai salah satu alat untuk mencapai keunggulan kompetitif, karena kualitas layanan merupakan salah satu faktor yang menentukan pemilihan sesuatu yang dapat memuaskan mahasiswa. Kepuasan mahasiswa akan tercapai apabila kualitas jasa yang diberikan sesuai kebutuhannya. Kualitas layanan merupakan tingkat keunggulan yang diharapkan dan pengendalian atas tingkat keunggulan untuk memenuhi keinginan mahasiswa. 
Menurut Wardana $(2010, \mathrm{p} 6)$ salah satu sistem informasi yang ada di perguruan tinggi adalah sistem informasi akademik. Dalam sistem informasi akademik ini tidak hanya mencakup sistem proses belajar mengajar saja, tetapi mencakup semua proses dari mulai seleksi calon mahasiswa sampai pelacakan lulusan. Keluaran dari sistem informasi ini diharapkan dapat memberikan informasi yang relevan dan up to date bagi stakeholder (calon mahasiswa, dosen, mahasiswa, administrasi, pengguna lulusan).

Sistem informasi manajemen pendidikan (informasi berbasis web) merupakan sarana untuk memperkenalkan kepada mahasiswa, dosen dan karyawan teknologi berbasis web, menggunakan serta mendapatkan layanan berbasis web. Dengan penggunaan sistem informasi Manajemen Pendidikan berbasis web diharapkan dapat menunjang pelaksanaan dan keberhasilan studi mahasiswa, serta pengembangan diri dosen maupun karyawan. Melihat hal tersebut dan meninjau pada penelitian sebelumnya, dilakukan penelitian lanjutan guna membuat rancangan sistem informasi untuk perguruan tinggi dalam use case diagram dengan berlandaskan beberapa teori rekayasa piranti lunak.

Dalam penelitian ini dicoba untuk membangun sebuah sistem informasi Akademik berbasis online yang mencakup administrasi akademik dan ruang dengan basis spesial yang diwujudkan dalam sebuah aplikasi komputer web base, mulai dari pembangunan basis data, perancangan sistem hingga implementasi sistem. Dengan dikembangkannya SIAKAD Online ini dapat menjadi alat dalam mengelola dan mencari informasi akademik secara efektif dan efisien.

Sekolah Tinggi Ilmu Ekonomi Surya Nusantara adalah Perguruan tinggi yang berada di provinsi Sumatera Utara, kota Pematangsiantar, dimana perguruan tinggi ini sedang melakukan beberapa pengembangan dalam meningkatkan mutu layanan akademik. Selama ini, Sekolah Tinggi Ilmu Ekonomi Surya Nusantara masih menggunakan sistem informasi manual dalam arti semua data akademik mahasiswa tersimpan dalam komputer lokal (Stand Alone) di kantor Biro Administrasi Akademik. Oleh karena itu maka peneliti merasa perlu untuk membantu dalam hal pengembangan sistem informasi akademik berbasis online pada Sekolah Tinggi Ilmu Ekonomi Surya Nusantara, Pematangsiantar.

\section{Ruang Lingkup}

Masalah dan pembatasan ruang lingkup dalam penelitian ini adalah sebagai berikut:

Tabel 1 Ruang lingkup Perancangan sistem

\begin{tabular}{|l|l|}
\hline Tahap 1 & $\begin{array}{l}\text { Penentuan bahasa } \\
\text { pemrograman yang akan } \\
\text { digunakan }\end{array}$ \\
\hline Tahap 2 & $\begin{array}{l}\text { Penentuan Relationship } \\
\text { Database Management } \\
\text { System (RDBMS) yang } \\
\text { akan digunakan }\end{array}$ \\
\hline Tahap 3 & $\begin{array}{l}\text { Penentuan Front End (FE) } \\
\text { Database }\end{array}$ \\
\hline Tahap 4 & $\begin{array}{l}\text { Penentuan Framework } \\
\text { yang akan digunakan }\end{array}$ \\
\hline
\end{tabular}

Dari tabel diatas dapat dilihat bahwa peneliti membuat tahapan-tahapan dalam penentuan dan pembatasan ruang lingkup penelitian yang dibuat, dimana pada hasil akhir penelitian ini akan menghasilkan produk yang usable dan dapat dipertanggung jawabkan.

Berikut ini adalah tabel 2 yang menjelaskan tools yang digunakan pada setiap tahapan dalam tabel 1.

Tabel 2 tools ruang lingkup perancangan sistem.

\begin{tabular}{|c|c|}
\hline Tahap 1 & $\begin{array}{c}\text { Html, php, javascript, } \\
\text { css, Bootstrap }\end{array}$ \\
\hline Tahap 2 & Mysql, Apache \\
\hline Tahap 3 & Phpmyadmin \\
\hline Tahap 4 & CodeIgniter \\
\hline
\end{tabular}


Tabel 2 ini langsung berisi berbagai alat yang digunakan dalam perancangan sistem informasi akademik online Sekolah Tinggi Ilmu Ekonomi Surya Nusantara, Pematangsiantar.

\section{Studi Pustaka}

Menurut Laudon (2012:16) sistem informasi adlah komponen-komponen yang saling berkaitan yang berkerja bersama-sama untuk mengumpulkan, mengolah, menyimpan dan menampilkan informasi untuk mendukung pengamblilan keputusan, koordinasi, pengaturan, analisa, dan visualisasi pada sebuah organisasi.

Menurut Whitten, bentley dan Ditman (2009:10) sistem informasi adalah pengaturan orang, data, proses dan informasi (TI) atau teknologi informasi yang berinteraksi untuk mengumpulkan, memproses, menyimpan dan menyediakan sebagai output informasi yang diperlukan untuk mendukung sebuah instansi atau organisasi.

Berdasarkan dua pernyataan diatas, maka dapat disimpulkan bahwa sistem informasi merupakan suatu sistem yang mempunyai kemampuan untuk mengumpulkan informasi dari semua sumber dan menggunakan berbagai media untuk menampilkan informasi.

\section{Pengertian Relationship Management System (RDBMS)}

Menurut Conolly dan Begg (2002:16) Database Management System adalah sebuah perangkat lunak yang memungkinkan pengguna mendefinisi, membentuk dan mengatur basis data dan yang mengendalikan akses ke basis data. DBMS berinteraksi dengan pengguna aplikasi program dan basis data, yang menyediakan fasilitas:

1. Data definition Language (DDL), yang berguna untuk menspesifikasikan tipe data, struktur dan constraint data. Semua spesifikasi disimpan di dalam basis data.

2. Data Manipulation Language (DML), yang berguna untuk memberikan fasilitas query data.

3. Pengendalian akses basis data, antara lain mengontrol keamanan sistem, mencegah useryang tidak memiliki hak akses untuk mengakses basis data, integrasi sistem, pengendalian share data, backup dan recovery system, katalog deskripsi data dalam basis data, teridiri dari deskripsi data yang berada dalam basis data.

4. Mekanisme view, yang berfungsi menampilkan kepada pengguna data yang diperlukan dan digunakan saja.

\section{Metode Perancangan}

Penelitian akan dilakukan dengan menggunakan metodologi SDLC (Bennett et al., 2002, p.48). Tahapan yang yang dilakukan adalah tahapan design atau perancangan. Pada tahap ini akan dibuatkan perancangan bisnis proses operasional akademik dalam bentuk use case diagram.

SDLC merupakan sebuah pendekatan sistematik (systematic approach) sebagai pemecahan masalah dan dikomposisi dalam beberapa fase, Mengacu pada tahp-tahap yang dilakukan dalam pengembangan aplikasinya. Tahapan dalam perancangan perangkat lunak adalah sebagai berikut:

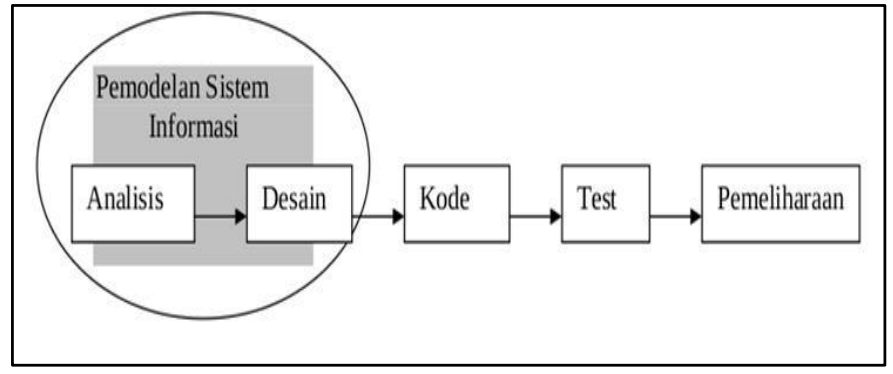

Gambar 1 Tahapan perancangan perangkat lunak

Sesuai dengan gambar diatas maka dapat di simpulkan bahwa tahapan pertama Analisis berarti pada tahapan ini maka dilakukan pencarian terhadap kebutuhan dari keseluruhan ssitem yang akan diaplikasikan kedalam perangkat lunak. Tahapan kedua, Desain berarti proses ini digunakan utuk mengubah kebutuhan-kebutuhan diatas menjadi representasi kedalam bentuk "blueprint" perangkat lunak yang akan dibuat. Tahapan ketiga, Kode berarti pengubahan bentuk desain menjadi bahasa 
pemrograman agar dapat dimengerti oleh mesin. Tahapan keempat, Test berarti uji coba terhadap semua fungsi perangkat lunak dan pada tahap ini dapat dilihat apakah ada fungsi yang mengalami "error", sedang hasil yang seharusnya adalah benar sesuai dengan kebutuhan dengan apa yang sudah didefinisikan sebelumnya. Tahapan kelima adalah Pemeliharaan yaitu pemelirahaan suatu software yang didalamnya dapat berarti pengembangan sesuai dengan kebutuhan saat ini.

\section{Test Case}

Adalah kasus uji yang memiliki probabilitas tinggi untuk menemukan kesalahan yang belum pernah ditemukan sebelumnya Perancangan test case adalah perancangan untuk menyediakan kemungkinan-kemungkinan yang cukup tinggi untuk menemukan kesalahan (sesuai dengan tujuan Uji coba) dengan jumlah waktu dan usaha yang minimum

Sebelum melakukan pengujian perlu dipersiapkan Test CaseTest Case terlebih dahulu agar diperoleh terlebih dahulu agar diperoleh kemungkinan tertinggi dalam menemukan kemungkinan tertinggi dalam menemukan kesalahan dengan waktu dan usaha yang kesalahan dengan waktu dan usaha yang minimum. Desain Test Case dapat dilakukan minimum. Desain Test Case dapat dilakukan melalui berbagai teknik pengujian diantaranya adalah:

1. White Box: pengujian untuk memperlihatkan cara kerja dari produk secara rinci sesuai dengan spesifikasinya.

2. Black Box: Pengujian untuk mengetahui apakah semua fungsi perangkat lunak telah berjalan semestinya sesuai dengan kebutuhan fungsional yang telah didefinisikan.

\section{Pengujian Black Box}

Metode Black Box memungkinkan perekayasa perangkat lunak mendapatkan serangkaian kondisi input yang sepenuhnya menggunakan semua persyaratan fungsional untuk suatu program.

Black Box dapat menemukan kesalahan dalam kategori berikut:

1. Fungsi-fungsi yang tidak benar atau hilang

2. Kesalahan interface

3. Kesalahan dalam strutur data atau akses basisdata eksternal

4. Inisialisasi dan kesalahan terminasi

5. validitas fungsional

6. kesensitifan sistem terhadap nilai input tertentu

7. batasan dari suatu data

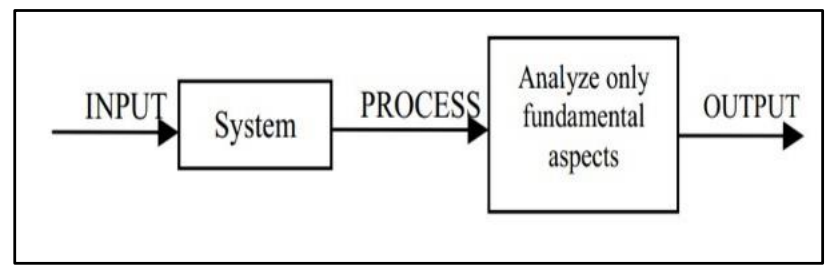

Gambar 2 Sitem Kerja dari Teknik Pengujian Black Box

\section{Hasil dan Pembahasan}

Seperti yang sudah dijelaskan pada studi pustaka dalam tabel 2 tools ruang lingkup perangan sistem, maka hasil dan pembahasan dapat dibuat seperti berikut ini:

\section{Analisis Pemodelan Sistem Informasi Akademik}

Dibagi menjadi 4 bagian yaitu:

1. Tools Analisys (Analisa Alat)

Perangkat lunak yang digunakan untuk merancang Sistem Informasi Akademik Online Sekolah Tinggi Ilmu Ekonomi Surya Nusantara ini adalah HTML, PHP, Javascript, CSS, Bootstrap, Mysql, xampp, phpmyadmin sebagai front end, dan framework-nya adalah CodeIgniter.

2. Process Analisys (Analisa Proses)

Pada bagian ini, peneliti menggunakan Use case Diagram untuk menggambarkan proses bisnis yang terjadi pada data akademik dengan menggunakan aplikasi Star UML. 


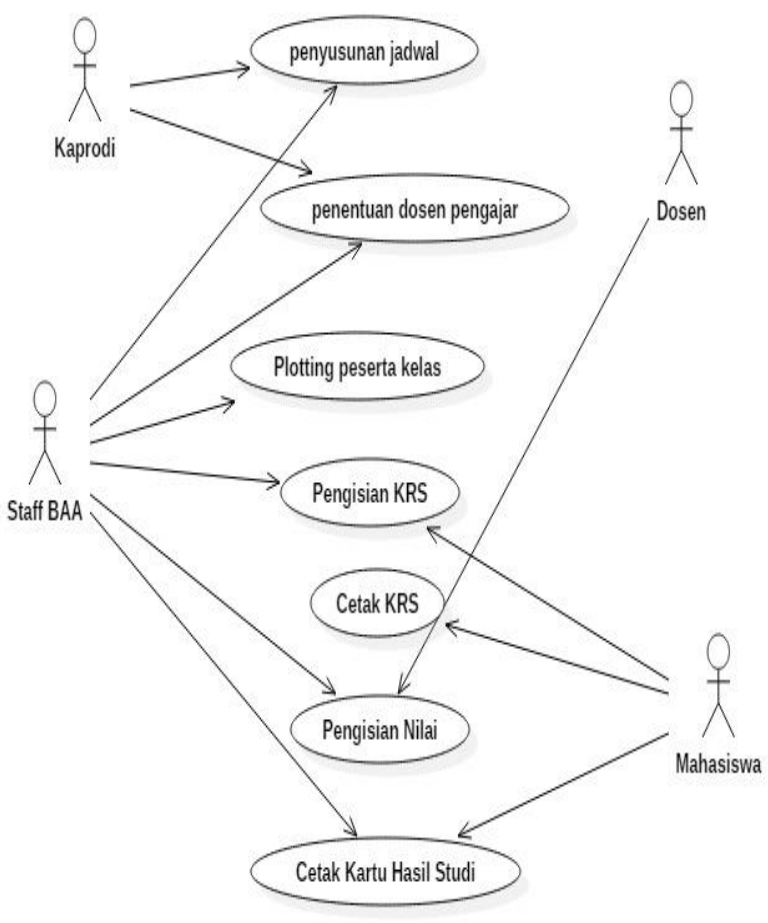

Gambar 3 Use case diagram proses bisnis

3. Database Analisys (Analisa Database)

Dengan menggunakan Mysql sebagai Database Management System (DBMS), maka dalam pengerjaan sebenarnya perlu dibuat nama database dan pengidentifikasian tabel-tabel yang digunakan. Dan memerlukan relationship antar table serta klasifikasi data type yang diteruskan dengan pembuatan dictionary terhadap field-field yang digunakan dalam menyimpan data.

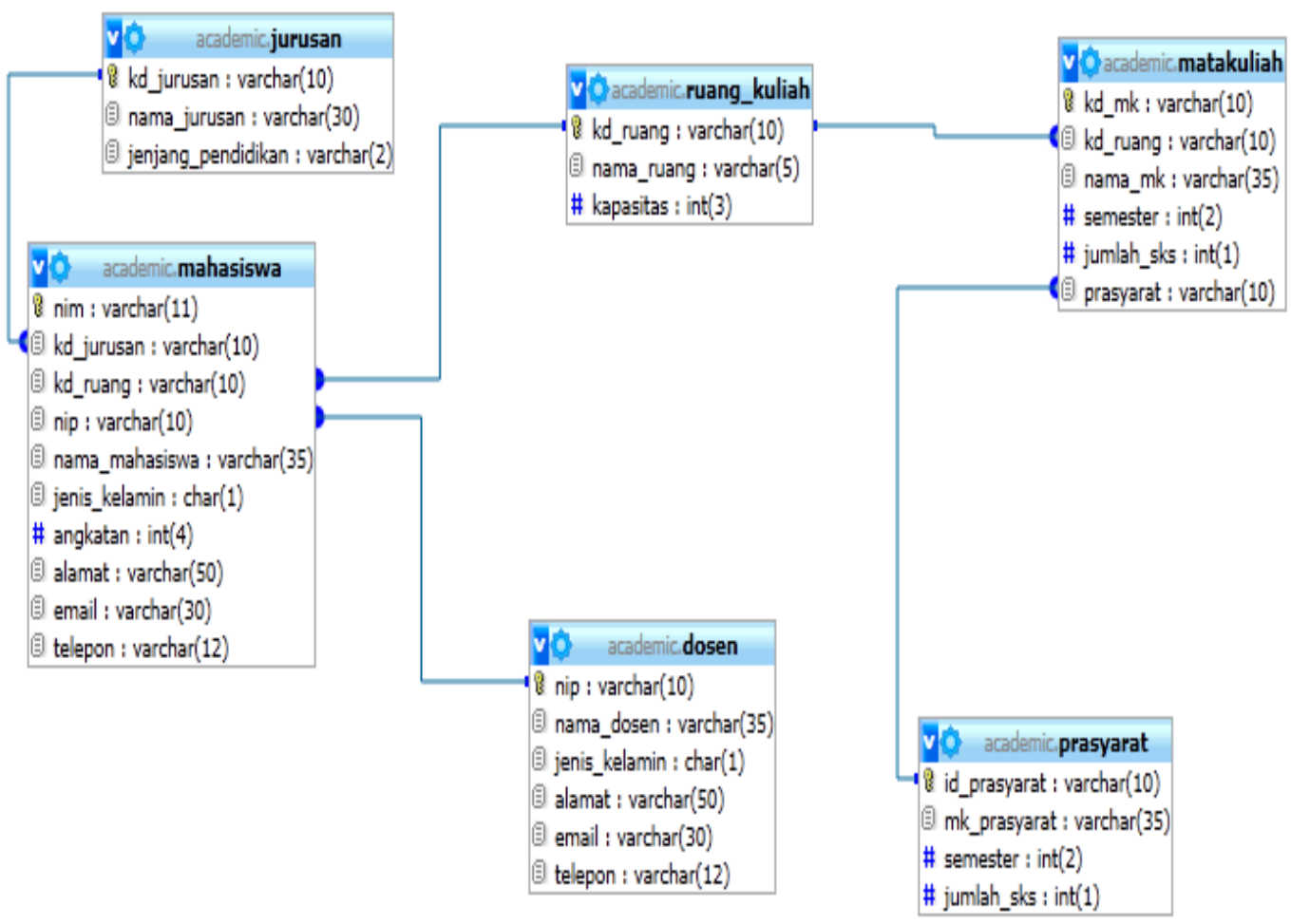

Gambar 3 Relatioship Table Diagram 


\section{Data Dictionary (Kamus Data)}

Kamus data merupakan sebuah daftar yang terorganisasi dari elemen data yang berhubungan dengan system, dengan definisi yang jelas dan teliti sehingga pemakai dan analis system akam memiliki pemahaman yang umum mengenai input, output, komponen penyimpan, dan bahkan kalkulasi inter-mediate. (Roger S. Pressman,1997

\section{Desain Pemodelan Sistem Informasi Akademik}

Pada tahapan ini peneliti menggambarkan alur diagramnya dengan menggunakan Use Case Diagram.

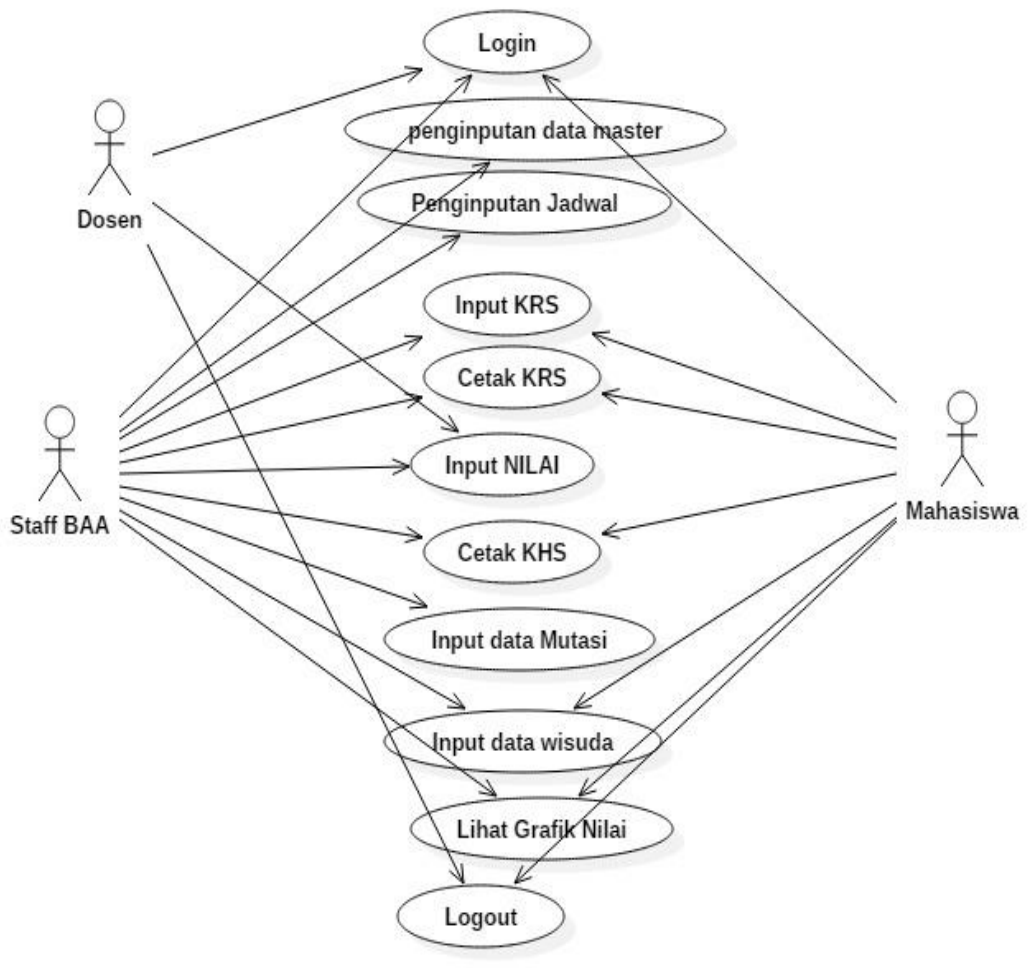

Gambar 4 Diagram Alur Sistem Informasi Akademik

Hal pertama yang harus dilakukan adalah login dengan menggunakan username dan password masing-masing dengan hak user yang telah diatur pada priviledge dan tersimpan pada database sedang untuk password-nya sendiri di enkripsi dengan menggunakan MD5.

Hal Kedua setelah login adalah penggunaan semua fungsi yang ada sesuai dengan hak pengguna yang telah diatur seperti terlihat pada gambar 4.

Dosen - Dapat menginput Nilai Mahasiswa yang Enrol/ pada kelas yang diajarnya.

Mahasiswa - Dapat Menginput Kartu Rencana Studi, mencetak Kartu Rencana Studi, Mencetak Kartu Hasil Studi, Mendaftar Wisuda dan dapat melihat grafik pencapaian akademiknya sendiri.

Staff Biro Administrasi (Administrator) - Dapat menginput data master (Data program studi, mata kuliah, dosen, mahasiswa), dapat menginput jadwal, dapat menginput KRS, dapat mencetak KRS, dapat menginput nilai, mencetak kartu hasil studi, menginput data mutasi, menginput data wisuda, melihat grafik enrollment mahasiswa terhadap program studi.

\section{Coding Pemodelan Sistem Informasi Akademik}

Proses ini membutuhkan beberapa aplikasi perangkat lunak tambahan diantaranya adalah: Sublime Text 3 dan Notepad serta Browser yang peneliti gunakan adalah Chrome buatan Google. Inc. 


\section{CodeIgniter}

CodeIgniter adalah aplikasi Open Source yan gberarti framework dengan model MVC (Model, View, Controller) untuk membuat web dinamis dengan menggunakan PHP.CodeIgniter memudahkan developer untuk membuat aplikasi web dengan cepat dan mudah. CodeIgniter dilisensikan dibawah lisensi Apache/BSD style open source. Dimana artinya adalah CodeIgniter ini adalah Opensource (dapat dipakai secara bebas).

Framework ini menjadi basis yang digunakan pada perancangan sistem informasi akademik online Sekolah Tinggi Ilmu Ekonomi Surya Nusantara. Dan didownload pada http://www.codeigniter.com.

\section{Hypertext Processor}

Php adalah Bahasa pemrograman Script server side yang didesain untuk pengembangan web. Pembatas yang paling umum adalah "<?php" untuk membuka dan "?>" Untuk menutup kode PHP.Tujuan dari pembatas ini adalah untuk memisahkan kode PHP dari kode di luar PHP, seperti HTML, Javascript.

Berikut ini adalah Coding untuk membuat model admin dengan nama file model_admins.php $<$ ?php if ( ! defined('BASEPATH')) exit('No direct script access allowed');

class Model_admins extends CI_Model \{

//query login

public function getLoginData(\$usr, \$psw)

\{

$$
\begin{aligned}
& \$ \mathrm{u}=\text { mysql_real_escape_string(\$usr); } \\
& \$ \mathrm{p}=\text { md5(mysql_real_escape_string }(\$ p s w)) ; \\
& \$ \mathrm{q} \_c e k \_l o g i n=\$ \text { this->db->get_where('admins', array('username' => \$u, 'password' => }
\end{aligned}
$$

$$
\text { if(count(\$q_cek_login->result()) >0) }
$$

\{

$$
\text { foreach(\$q_cek_login->result() as \$qck) }
$$

Data coding diatas adalah penggalan dari model admin yang membentuk proses login administrator.

\section{Test Pemodelan Sistem Informasi Akademik}

Proses ini membutuhkan browser untuk menjalankannya. Pengujian perangkat lunak adalah elemen kritis dari jaminan kualitas perangkat lunak dan merepresentasikan kajian pokok dari spesifikasi, desain dan pengkodean.

Tabel 3 Black Box Testing Admin Sistem Informasi Akademik

\begin{tabular}{|l|l|l|l|}
\hline No & \multicolumn{1}{|c|}{$\begin{array}{c}\text { Rancangan } \\
\text { Proses }\end{array}$} & \multicolumn{1}{|c|}{ Hasil yang diharapkan } & Hasil \\
\hline 1 & $\begin{array}{l}\text { Mengisi form } \\
\text { Login dan klik } \\
\text { tombol login }\end{array}$ & Masuk Halaman Utama & Sesuai \\
\hline 2 & $\begin{array}{l}\text { Klik Menu Master } \\
\text { da nisi form } \\
\text { Master }\end{array}$ & $\begin{array}{l}\text { Menampilkan pilihan menu master } \\
\text { dan Simpan Data }\end{array}$ & Sesuai \\
\hline 3 & $\begin{array}{l}\text { Klik Menu } \\
\text { Transaksi }\end{array}$ & $\begin{array}{l}\text { Menampilkan Pilihan Menu } \\
\text { Transaksi da nisi data transaksi }\end{array}$ & Sesuai \\
\hline 4 & $\begin{array}{l}\text { Klik Menu } \\
\text { laporan }\end{array}$ & $\begin{array}{l}\text { Menampilkan pilihan menu } \\
\text { laporan dan cetak }\end{array}$ & Sesuai \\
\hline 5 & Klik menu grafik & Menampilkan grafik mahasiswa & sesuai \\
\hline 6 & Klik Logout & Keluar dari halaman utama & sesuai \\
\hline
\end{tabular}


Tabel 4 Black Box Testing Dosen Sistem Informasi Akademik

\begin{tabular}{|l|l|l|l|}
\hline No & \multicolumn{1}{|c|}{$\begin{array}{c}\text { Rancangan } \\
\text { Proses }\end{array}$} & Hasil yang diharapkan & Hasil \\
\hline 1 & $\begin{array}{l}\text { Mengisi form Login } \\
\text { dan klik tombol } \\
\text { login }\end{array}$ & Masuk Halaman Utama & Sesuai \\
\hline 2 & $\begin{array}{l}\text { Klik Menu Akademik } \\
\text { dan klik mata kuliah } \\
\text { atau jadwal }\end{array}$ & $\begin{array}{l}\text { Menampilkan pilihan menu } \\
\text { akademik dan menampilkan } \\
\text { data mata kuliah semester } \\
\text { atau jadwal kuliah semester }\end{array}$ & Sesuai \\
\hline 3 & $\begin{array}{l}\text { Klik Menu Isi Nilai } \\
\text { dan klik tombol } \\
\text { simpan }\end{array}$ & $\begin{array}{l}\text { Menampilkan form isi Nilai } \\
\text { dan data tersimpan }\end{array}$ & Sesuai \\
\hline 4 & Klik Logout & Keluar dari halaman utama & sesuai \\
\hline
\end{tabular}

Tabel 5 Black Box Testing Mahasiswa Sistem Informasi Akademik

\begin{tabular}{|l|l|l|l|}
\hline No & \multicolumn{1}{|c|}{$\begin{array}{c}\text { Rancangan } \\
\text { Proses }\end{array}$} & \multicolumn{1}{|c|}{ Hasil yang diharapkan } & Hasil \\
\hline 1 & $\begin{array}{l}\text { Mengisi form Login } \\
\text { dan klik tombol } \\
\text { login }\end{array}$ & Masuk Halaman Utama & Sesuai \\
\hline 2 & $\begin{array}{l}\text { Klik Menu Mata } \\
\text { Kuliah }\end{array}$ & $\begin{array}{l}\text { Menampilkan data } \\
\text { matakuliah sesuai semester } \\
\text { pilihan }\end{array}$ & Sesuai \\
\hline 3 & Klik Menu Isi KRS & $\begin{array}{l}\text { Menampilkan Mata Kuliah } \\
\text { dan Memilih Mata Kuliah }\end{array}$ & Sesuai \\
\hline 4 & Klik Menu Lihat KRS & $\begin{array}{l}\text { Menampilkan KRS sesuai } \\
\text { dengan semester pilihan }\end{array}$ & Sesuai \\
\hline 5 & Klik Menu Jadwal & $\begin{array}{l}\text { Menampilkan jadwal sesuai } \\
\text { dengan tahun akademik dan } \\
\text { semester }\end{array}$ & Sesuai \\
\hline 6 & $\begin{array}{l}\text { Klik Menu KHS dan } \\
\text { klik download KHS }\end{array}$ & $\begin{array}{l}\text { Menampilkan Kartu Hasil } \\
\text { Studi sesuai dengan Tahun } \\
\text { akademik dan semester dan } \\
\text { download KHS ke PDF }\end{array}$ & Sesuai \\
\hline 7 & Klik Menu Wisuda & Menampilkan data Wisuda & Sesuai \\
\hline 8 & Klik Menu Grafik & $\begin{array}{l}\text { Menampilkan Grafik berupa } \\
\text { chart pencapaian akademik } \\
\text { dengan referesnsi IPS }\end{array}$ & Sesuai \\
\hline 7 & Klik Logout & Keluar dari halaman utama & sesuai \\
\hline
\end{tabular}

Sesuai dengan black Box testing, yang menetapkan hanya ada dua pilihan berupa data Boolean, maka pengujian diatas dapat dinyatakan secara valid sesuai dengan temuan ketika menjalankan program secara berkala.

\section{Maintenance Pemodelan Sistem Informasi Akademik}

Pemelirahaan perangkat lunak adalah proses umum pengubahan/pengembangan perangkat lunak setelah diserahkan kepada konsumen. Perubahan mungkin berupa perubahan sederhana untuk membetulkan eror koding atau perubahan yang lebih ekstensif untuk membetulkan error perancangan/perbaikan signifikan untuk membetulkan error spesifikasi/akomodasi persyaratan baru.

Pada proses ini peneliti merasa maintenance ini nantinya akan mengadopsi 4 bentuk maintenance inti yaitu: 
1. Corrective Maintenance

2. Adaptive Maintenance

3. Perfective Maintenance

4. Preventive Maintenance

\section{Kesimpulan}

Dari hasil perancangan diatas maka, dapa disimpulkan bahwa untuk membuat perancangan sebuah sistem informasi akademik, diperlukan beberapa perangkat lunak tambahan seperti text editor, DBMS, browser dimana keterkaitan perangkat lunak ini sangat diperlukan mulai dari tahap analisis, tahap desain, tahap pengkodean, tahap pengujian, hingga tahap pemelirahaan. Dan perancangan sistem ini dapat berjalan dengan normal, stabil sesuai dengan hasil pengujian menggunakan black box testing dimana hampir semua fungsi telah sesuai dengan kebutuhan dan telah sesuai dengan tahapan desain.

\section{Referensi}

1. Bennett, S., McRobb, S., dan Farmer, R., (2002). Object-Oriented Systems Analysis and Design (2nd edition). London: McGraw-Hill.

2. Laudon, Jane. P. Management Information System, Managing the Digital Firm $12^{\text {th }}$ Edition. Pearson. 2012

3. Mohd. Ehmer Khan - Different Forms of Software Testing Techniques for Finding Error, tahun 2010

4. Wardana, S. Hut., M.Si, Menjadi Master PHP dengan Framework Codeigniter, Elex Media Komputindo. 2010

5. Whitten, Bentley, Ditman, (2009), Systems Analysis \& Desain Method, McGraw-Hill/Irwin 
